\title{
CYCLIC TENSILE STRAIN ENHANCES HUMAN MESENCHYMAL STEM CELL SMAD 2/3 ACTIVATION AND TENOGENIC DIFFERENTIATION IN ANISOTROPIC COLLAGEN-GLYCOSAMINOGLYCAN SCAFFOLDS
}

\author{
W.K. Grier ${ }^{1}$, A.S. Moy ${ }^{2}$ and B.A.C. Harley ${ }^{1,3, *}$ \\ ${ }^{1}$ Department of Chemical and Biomolecular Engineering, University of Illinois at Urbana-Champaign, \\ Urbana, IL 61801, USA \\ ${ }^{2}$ Department of Bioengineering, University of Illinois at Urbana-Champaign, Urbana, IL 61801, USA \\ ${ }^{3}$ Carl R. Woese Institute for Genomic Biology, University of Illinois at Urbana-Champaign, Urbana, IL 61801, USA
}

\begin{abstract}
Orthopaedic injuries, particularly those involving ligaments and tendons, are some of the most commonly treated ailments in the United States and are associated with both high costs and poor outcomes. Regenerative medicine strategies for tendon injuries could be enhanced by three-dimensional biomaterials that can promote cell alignment and pro-tenogenic differentiation of patientderived MSCs. We have previously described a collagenglycosaminoglycan (CG) scaffold possessing aligned structural features able to promote bone marrow MSC differentiation towards a tenogenic lineage, in the absence of growth factor supplementation. We aimed to employ a bioreactor to enhance MSC tenogenic differentiation within the aligned CG scaffold via cyclic tensile strain (CTS), and further to evaluate the relative effects of strain cycle duration and extended application of repeated cycles of CTS on MSC response. Human MSCs were cultured in CG scaffolds for up to $6 \mathrm{~d}$ under static (unloaded) or cyclic tensile strain $(1 \mathrm{~Hz})$ for 10 min every $6 \mathrm{~h}$. Time-dependent activation of ERK $1 / 2$ and p38 mechanotransduction pathways was observed within each $6 \mathrm{~h}$ strain cycle. MSCs remained viable throughout the experiment and application of CTS robustly upregulated the expression of tendon-specific extracellular matrix proteins and phenotypic markers. Simultaneously, CTS promoted increased phosphorylation of Smad 2/3, suggesting a link between tensile stimulation and TGF- $\beta$ family growth factor production. Together, we demonstrated the design, fabrication and validation of a high-throughput tensile stimulation bioreactor to increase MSC tenogenic differentiation in porous CG scaffolds.
\end{abstract}

Keywords: collagen scaffold, mechanotransduction, bioreactor, cyclic tensile strain, mesenchymal stem cell, tendon.
*Address for correspondence:

B.A.C. Harley

Department of Chemical and Biomolecular Engineering Carl R. Woese Institute for Genomic Biology

University of Illinois at Urbana-Champaign

110 Roger Adams Laboratory

600 S. Mathews Ave

Urbana, IL 61801, USA

Telephone number: +12172447112

Fax number: +12173335052

Email: bharley@illinois.edu

\section{Introduction}

Tendon and ligament injuries pose a significant challenge for medical professionals, affecting a wide range of individuals, from athletes to the elderly, with more than 32 million occurrences every year in the USA alone (Breidenbach et al., 2013; James et al., 2008; Liu et al., 2008; Xu and Murrell, 2008). While not all injuries require surgical intervention, many classes of these injuries, such as rotator cuff and Achilles tendon tears, together account for more than 100,000 surgeries per year in the USA (Pedowitz and Kirwan, 2013; Vitale et al., 2007) and can show wide ranges of re-failure rates based on patient demographics (Galatz et al., 2006). Generally, tendon and ligament defects display poor intrinsic healing properties, requiring surgical intervention and result in fibrous scar tissue formation with misaligned extracellular matrix (ECM) and inferior mechanical properties, leading to high rates of injury recurrence (James et al., 2008; Liu et al., 2008; Xu and Murrell, 2008). As a result, tissue engineering solutions, particularly those that are able to address the geometrically aligned and mechanically dynamic nature of these tissues, are increasingly researched, in order to address the shortcomings of current surgical procedures and improve outcomes of injuries.

Collagen-glycosaminoglycan (CG) scaffolds have been used in a wide variety of tissue engineering applications for skin, peripheral nerve and cartilage tissue engineering as well as 3D environments for in vitro studies of cell-matrix interactions (cell migration and contraction) behaviour (Farrell et al., 2006; Harley et al., 2007a; Harley et al., 2008; Harley et al., 2004; O’Brien et al., 2005; Schulz Torres et al., 2000; Yannas et al., 1989). We have recently developed a fabrication method to produce anisotropic CG 
scaffolds composed of an aligned ellipsoidal pore structure for applications in tendon repair (Caliari and Harley, 2011). The anisotropic scaffold microstructure promotes cell alignment along the long axis of the ellipsoidal pores (Caliari and Harley, 2011), resists tenocyte-mediated contraction and loss of tenogenic gene expression profiles (Caliari et al., 2012; Grier et al., 2017). It also promotes mesenchymal stem cell (MSC) elongation and differentiation towards a tenogenic phenotype, in the absence of applied cyclic strain or exogenous growth factors (Caliari and Harley, 2014a; Caliari and Harley, 2011). While promising, these initial findings suggested the need to improve the structural mechanic of the materials. By incorporating structural reinforcement elements, the scaffold can be made mechanically more robust for in vivo applications (Mozdzen et al., 2016; Mozdzen et $a l ., 2017)$. As a result, there is a specific need to identify culture conditions to enhance tenogenic differentiation and promote extracellular matrix remodelling, in order to ensure the scaffold would remain structurally competent and fully integrate into a wound repair site.

Mechanical stimulation is a significantly important factor in musculoskeletal tissue engineering applications. Matrix mechanical cues have shown to be important tools for altering stem cell differentiation profiles (Engler et al., 2004; Hao et al., 2013; Janmey and McCulloch, 2007). Of particular interest to tendon applications, mechanical force has been shown to be a critical element in the recruitment of scleraxis-expressing cells to the tendonbone-junction enthesis during development (Chen et al., 2012; Schweitzer et al., 2010), as well as in promoting rehabilitative healing of the enthesis after injury (Galloway et al., 2013; Thomopoulos et al., 2008). In addition to playing a role in development, mechanotransduction pathways, activated through microstructural cues and applied mechanical stimulation, can influence stem cell activation and differentiation. Substrate alignment and stiffness can activate canonical RhoA/ROCK1 and FAK pathways to promote MSC differentiation towards musculoskeletal lineages (Allen et al., 2012; Andalib et al., 2013; Kanazawa et al., 2014; Sarasa-Renedo et al., 2006; Xu et al., 2011; Xu et al., 2012). As a result of this increased focus on mechanical cues, bioreactors capable of providing mechanical strain to cell-seeded biomaterials are of particular interest in recent tendon and ligament tissue engineering applications. Applied cyclic tensile strain can promote the phosphorylation of ERK 1/2 via RhoA activation (Laboureau et al., 2004) and the upregulation of procollagen mRNA (Papakrivopoulou et al., 2004). As a result, many studies have focused on identifying strain profiles to prolong ERK $1 / 2$ activation, in order to promote cell-mediated ECM biosynthesis (Paxton et al., 2012). The p38 mitogen-activated protein kinase pathway inhibits ERK 1/2 activation (Papakrivopoulou et al., 2004; Weinbaum et al., 2013), suggesting an alternate target for promoting ECM biosynthesis. Paxton et al. demonstrated that MSCs in fibrin hydrogels, for ligament repair, showed increased ERK 1/2 activation when exposed to an intermittent cyclic tensile strain paradigm, where the constructs were subjected to $10 \%$ strain at $1 \mathrm{~Hz}$ for just 10 min every 6 h (Paxton et al., 2012). Maximal reactivation and sustained activation of ERK 1/2 required $6 \mathrm{~h}$ of rest after the initial application of strain, thought to be a mediated by residual phosphorylated p38 inhibiting ERK 1/2 re-phosphorylation.

Smad 2/3 and Smad 1/5/8 pathways play a crucial role in the development of musculoskeletal tissues, primarily regulating the action of the TGF- $\beta$ and BMP family of growth factors during cell differentiation and activity (Allen et al., 2012; Maeda et al., 2011; Miyazono, 2000; Shi and Massague, 2003). Activation of Smad 1/5/8 by BMP-2 plays an important role in MSC osteogenic differentiation, while the activation of Smad $2 / 3$ by TGF- $\beta$ plays a critical role in tendon and ligament development (Maeda et al., 2011; Shen et al., 2013; Towler and Gelberman, 2006). Also, recent work by Berthet et al. showed that activated Smad 3 binds to the Scleraxis (SCX) and Mohawk (MKX) transcriptional regulators during tendon matrix development (Berthet et al., 2013). Efforts by the Alliston laboratory also reported that crosstalk between mechanical stimuli and growth factor supplementation could activate Smad $1 / 5 / 8$ as well as drive a feedback loop driven by subsequent endogenous growth factor production to enhance musculoskeletal differentiation (Allen et al., 2012). While the vast majority of those studieshave primarily employed 2D culture environment, new efforts to define linkages between the mechanical microenvironment of the cell, Smad activation and endogenous growth factor production, as well as subsequent stem cell differentiation and tissue development are necessary.

Here, we describe the development of a bioreactor system to facilitate the culture and analysis of MSC-seeded collagen-GAG scaffolds under physiological levels of cyclic tensile strain (CTS). Based on a design previously described by the Levenston laboratory (Doroski et al., 2010; Vanderploeg et al., 2008), this bioreactor allows parallel culture of 24 distinct biomaterial constructs in individually isolated wells. Many early bioreactor systems employed clamps to grip and pull on the ends of cell-seeded materials (Bosworth et al., 2014), though many clamping approaches require the ends of the substrate to be crushed or significantly deformed to prevent slippage, which is not suitable for extended culture of porous biomaterial scaffolds. As a result, recent efforts have focused on the use of yarn or textile style biomaterials that show less deformation from clamps or can be looped or tied around loading posts (Bosworth et al., 2014; Paxton et al., 2012). Unfortunately, neither of these approaches is suitable for use with porous biomaterials. Doroski et al. recently described a potentially translatable approach where a hydrogel substrate was infiltrated into porous polymeric end-blocks that could be securely griped within a bioreactor (Doroski et al., 2010). Here, we used polydimethylsiloxane (PDMS) to infiltrate both the ends of the CG scaffolds as well as a porous polymeric end-blocks to facilitate immobilisation of the porous CG scaffold within the bioreactor. We report the effect of cyclic tensile strain on activation of MSC mechanotransduction pathways as well as subsequent MSC proliferation and pro-tenogenic differentiation in extended culture in vitro. 


\section{Materials and Methods}

All materials were purchased from Sigma-Aldrich (St Louis, MO, USA) unless otherwise specified.

\section{Fabrication of collagen-GAG scaffolds}

Type I microfibrillar collagen from bovine tendon (Collagen Matrix Inc., Oakland, NJ, USA) and chondroitin sulphate from shark cartilage were homogenised in $0.05 \mathrm{M}$ acetic acid at a ratio of collagen to glycosaminoglycan of $11.25: 1$ (Madaghiele et al., 2008; Yannas et al., 1989). Anisotropic scaffolds were fabricated through lyophilisation, using a previously described directional solidification approach (Caliari and Harley, 2011; O'Brien et al., 2004). Briefly, degassed CG suspension was pipetted into wells $(6 \mathrm{~mm}$ diameter, $30 \mathrm{~mm}$ deep) within a polytetrafluoroethylene (PTFE) mould with a copper bottom that was subsequently placed on a pre-cooled $\left(-10{ }^{\circ} \mathrm{C}\right)$ freeze-dryer shelf (VirTis, Gardner, NY, USA). The mismatch in thermal conductivity between the PTFE body and copper base of the mould promotes unidirectional heat transfer through the more conductive copper (Caliari and Harley, 2011). The CG suspension was frozen at $-10^{\circ} \mathrm{C}$ for $2 \mathrm{~h}$ and then sublimated at $0{ }^{\circ} \mathrm{C}$ and $26.66 \mathrm{~Pa}$ to remove the ice crystals, resulting in a dry porous scaffold. Following lyophilisation, scaffolds were crosslinked by dehydrothermal (DHT) crosslinking in a $105{ }^{\circ} \mathrm{C}$ oven (Welch, Niles, IL, USA) under vacuum $(<3.333 \mathrm{kPa})$ for $24 \mathrm{~h}$ and then stored until use in a desiccator.

\section{Bioreactor design}

Inspired by a previous design from the Levenston laboratory (Doroski et al., 2010), the cyclic tensile strain bioreactor system consisted of a sliding rake system controlled by a linear motor actuator and controller (Fig. 1A) (Pololu Corp., Las Vegas, NV, USA). The motor was controlled using a custom $\mathrm{C} \#$ program. A total of 24 modular wells were constructed with a static loading post at one end. The modular nature of the wells allows for easy adaptation to various scaffold sizes and geometries. For static controls, a separate set of wells of identical geometry. with two posts at a fixed distance, was constructed. The ends of dry CG scaffolds were embedded into hollow end-blocks fabricated by additive manufacturing that could be affixed to the static and loading posts within the bioreactor. In order to measure scaffold strain as a function of bioreactor settings, dry scaffolds were marked with black India Ink (Dick Blick Art Materials, Galesburg, IL, USA) (Fig. 1B). A video was then taken while the bioreactor was in motion using a Canon EOS-5D Mark II SLR 21.1 MP digital camera (Canon, Tokyo, Japan). Individual frames were converted to grayscale image sequences and imported into ImageJ, where the distance between each mark was measured using the object tracker plugin. Overall strain was calculated by normalising the distance between each point to the initial length and then averaging across the entire scaffold (Fig. 1C). Due to tolerances required to insert the scaffolds into the bioreactor, a discrepancy in applied system strain (movement of the sliding rake system) and resultant scaffold deformation was observed. Throughout the experiment, we will refer to the magnitude of applied strain as the movement of the sliding rake system.

\section{Embedding scaffolds into loading blocks}

Hollow end-blocks were fabricated from acetyl-butylstyrene (ABS) using a Makerbot Replicator 2X 3D printer (MakerBot Industries, Brooklyn, NY, USA). One side of the end-blocks was designed to fit over the loading posts of the bioreactor system ( $5 \mathrm{~mm}$ diameter), while the other end was open to allow for the ends of the scaffolds to be inserted $(6 \times 6 \mathrm{~mm})$. End-blocks were filled with a $5: 1$ solution of polydimethylsiloxane (PDMS) catalyst (Hisco Inc., Houston, TX, USA). After allowing the PDMS to cure at $37^{\circ} \mathrm{C}$ for $45 \mathrm{~min}, 5 \mathrm{~mm}$ of one end of $25 \mathrm{~mm}$ long CG scaffolds were inserted into the PDMS in the end-block and allowed to cure overnight at $37^{\circ} \mathrm{C}$. This procedure was repeated with the opposite side of the scaffold, resulting in a $15 \mathrm{~mm}$ gauge length (Fig. 1B).

\section{Scaffold crosslinking}

After embedding, scaffolds were immersed in $-100 \%$ ethanol for $6 \mathrm{~h}$, followed by washing with phosphatebuffered saline (PBS) overnight. The scaffolds were then crosslinked by carbodiimide chemistry. Scaffolds were soaked for $2 \mathrm{~h}$ at room temperature in a solution of 1-ethyl3-[3-dimethylaminopropyl] carbodiimide hydrochloride (EDC) and N-hydroxysulfosuccinimide (NHS) at a molar ratio of $5: 2: 1$, EDC : NHS : COOH, in PBS (Harley et al., 2007b; Olde Damink et al., 1996). After crosslinking, the scaffolds were washed twice with sterile PBS before seeding.

\section{Critical point drying and SEM analysis}

Scaffold microstructure was examined after carbodiimide crosslinking. First, each scaffold was dehydrated using a series of washes with ethanol from $10 \%$ to $100 \%$ concentration, followed by subjection to critical point drying (CPD) using a Samdri-PVT-3D (Tousimis, Rockville, MD, USA). The CPD process replaces the ethanol with liquid $\mathrm{CO}_{2}$ and held above $6.895 \mathrm{kPa}$ and $31{ }^{\circ} \mathrm{C}$, allowing the $\mathrm{CO}_{2}^{-}$to be gently removed as a gas from the system with minimal structural deformation. The samples were then sectioned by cutting and mounted on carbon tape before sputter coating with a gold/palladium mixture. Imaging was then carried out with a Philips XL30 ESEM-FEG (FEI Company, Hillsboro, OR, USA) at $5 \mathrm{kV}$ with a secondary electron detector.

\section{Human mesenchymal stem cell culture}

Human bone marrow-derived MSCs were purchased from Lonza (Walkersville, MD, USA). Cells from multiple lots, originating from separate donors, were combined to account for any donor-specific responses. The MSCs were cultured at $37^{\circ} \mathrm{C}$ and $5 \% \mathrm{CO}_{2}$ in a complete MSC growth medium, consisting of low-glucose Dulbecco's Modified Eagle Medium with 10 vol \% MSC foetal bovine serum and 1 vol \% antibiotic-antimitotic (Thermo Fisher, Waltham, MA, USA), fed twice a week and used at passage 6 for all experiments. 


\section{Culture of MSC-seeded CG scaffolds}

CG scaffolds embedded in end-blocks $(6 \mathrm{~mm}$ diameter, $15 \mathrm{~mm}$ gauge length) were seeded with MSCs using a previously validated static seeding method (O'Brien et al., 2005). Briefly, scaffolds were partially dried with Kimwipes and seeded with $3.0 \times 10^{5}$ MSCs per $60 \mu \mathrm{L}$ medium $(3 \times 20 \mu \mathrm{L}$ drops along scaffold length) in the individual wells of the bioreactor system. Cells were allowed to attach for $1 \mathrm{~h}$ before submerging them in medium; constructs were given an additional $24 \mathrm{~h}$ before application of CTS to ensure cell attachment. Cell-seeded scaffolds in the CTS groups were subjected to continuous cyclic tensile strain $(10 \%$ strain at $1 \mathrm{~Hz})$ for $10-120 \mathrm{~min}$, to demonstrate the activation of mechanotransduction pathways. For examining extended culture MSC differentiation, scaffolds were subjected to intermittent CTS (10\% strain, $1 \mathrm{~Hz}$ ) for 10 min every $6 \mathrm{~h}$ for up to $6 \mathrm{~d}$ to allow for sufficient cellular refractory period to ensure prolonged effects (inspired by Paxton et al. 2012). Cellseeded scaffolds were cultured at $37{ }^{\circ} \mathrm{C}$ and $5 \% \mathrm{CO}_{2}$ and fed twice a week with complete MSC growth medium. For static controls, scaffolds were placed into a separate set of wells of identical geometry to the bioreactor but which contained two posts at a fixed distance equal to that of the bioreactor at rest. During the experiment, scaffolds were collected for further analysis immediately after the conclusion of a strain cycle by physically separating them from the end-blocks by cutting.

\section{Protein extraction, gel electrophoresis and immunoblotting}

Following stretch, scaffolds were briefly washed in warm phosphate-buffered saline, dry blotted, submerged in RIPA buffer with $1: 100$ dilutions of protease and phosphatase II and III inhibitor cocktails and kept on ice for $30 \mathrm{~min}$, with regular agitation. Total protein concentration was determined by the BCA assay kit (Pierce). For gel electrophoresis, $10 \mu \mathrm{g}$ of protein from each sample was solubilised in an equal volume of Laemmli sample buffer and heated at $90{ }^{\circ} \mathrm{C}$ for $10 \mathrm{~min}$. Total lysates were separated by tris-glycine gel electrophoresis on 4-20\% gradient gels at $150 \mathrm{~V}$ for $90 \mathrm{~min}$. Following electrophoresis, a semi-dry transfer was used to transfer proteins to a nitrocellulose membrane (GE Healthcare) at $15 \mathrm{~V}$ for $15 \mathrm{~min}$. Membranes were then blocked for $1 \mathrm{~h}$ in $5 \%$ milk in tris-bufferedsaline $+0.1 \%$ tween (TBST). Membranes were incubated overnight at $4{ }^{\circ} \mathrm{C}$ with the appropriate primary antibody in $5 \%$ bovine serum albumin in TBST. Next, the membranes were washed three times in TBST, before incubation for $1 \mathrm{~h}$ at room temperature with HRP-linked goat anti-rabbit IgG secondary antibody (1 : 5,000; Cell Signaling, Danvers, MA, USA) in TBST. Antibody binding was detected using SuperSignal West Pico or Femto Chemiluminescent Substrate (Thermo Fisher, Waltham, MA,USA). After probing, membranes were stripped with OneMinute ${ }^{\circledR}$ Western Blot Stripping Buffer (GM Biosciences, Rockville, MD, USA) and re-probed up to two times, following the same protocol. Antibodies were purchased from Cell Signaling (Danvers, MA, USA): ROCK1 (4035), FAK (3285), pFAK (3283), p38 (8690), p-p38 (9215), ERK 1/2 (4695), pERK 1/2 (4370), Smad 2/3 (8685), pSmad 2/3 (8828), Smad 1 (6944), pSmad 1/5/8 (9511), $\beta$-actin (4967). Imaging was carried out using an ImageQuant LAS 4010 system (GE Healthcare) and ImageJ was used for band intensity quantification.

\section{Quantifying cell number and metabolic activity}

A previously described DNA quantification assay was used to determine the number of cells attached to the scaffold (Kim et al., 1988). Briefly, scaffolds were washed in PBS to remove unattached cells, placed in a papain solution to digest the scaffold and lyse the cells in order to expose their DNA, then incubated with a Hoechst 33258 dye (Invitrogen, Carlsbad, CA, USA) to fluorescently

Table 1. PCR primer sequences.

\begin{tabular}{|c|c|c|}
\hline Transcript & Sequence & Reference \\
\hline COL1A2 & $\begin{array}{l}\text { Forward: 5' - TGACCTCAAGATGTGCCACT - 3' } \\
\text { Reverse: 5' - - ACCAGACATGCCTCTTGTCC - 3' }\end{array}$ & (Pauly et al., 2010) \\
\hline COL3A1 & $\begin{array}{l}\text { Forward: 5' '- GCTGGCATCAAAGGACATCG - 3' } \\
\text { Reverse: 5' - TGTTACCTCGAGGCCCTGGT - 3' }\end{array}$ & (Pauly et al., 2010) \\
\hline COMP & $\begin{array}{l}\text { Forward: 5' - GCAACACGGACGAGGACAAG - 3' } \\
\text { Reverse: 5' - CGCCATCACTGTCCTTCTGG - 3' }\end{array}$ & (Klatte-Schulz et al., 2013) \\
\hline $\mathrm{DCN}$ & $\begin{array}{l}\text { Forward: 5' - CGCCTCATCTGAGGGAGCTT - 3' } \\
\text { Reverse: 5' - TACTGGACCGGGTTGCTGAA - 3' }\end{array}$ & (Pauly et al., 2010) \\
\hline $\mathrm{SCXB}$ & Purchased from Qiagen (sequence unavailable) & (Caliari and Harley, 2014b) \\
\hline MKX & $\begin{array}{l}\text { Forward: 5' - CGTATTGGAAGGAGATCAACG - 3' } \\
\text { Reverse: 5' - GGACGACTTCTGGATGATGC - 3' }\end{array}$ & (Lorda-Diez et al., 2013) \\
\hline $\mathrm{TNC}$ & $\begin{array}{l}\text { Forward: 5' - TTCACTGGAGCTGACTGTGG - 3' } \\
\text { Reverse: 5' - TAGGGCAGCTCATGTCACTG - 3' }\end{array}$ & (Pauly et al., 2010) \\
\hline GAPDH & $\begin{array}{l}\text { Forward: 5' - CCATGAGAAGTATGACAACAGCC - 3' } \\
\text { Reverse: 5' - CCTTCCACGATACCAAAGTTG - 3' }\end{array}$ & (Pauly et al., 2010) \\
\hline
\end{tabular}


label double-stranded DNA. Fluorescence intensities (352/461 nm excitation/emission) from each sample were read using a fluorescence spectrophotometer (Tecan, Männedorf, Switzerland) and compared to a standard curve created from known numbers of MSCs.

The mitochondrial metabolic activity of the MSCs within each scaffold was determined through the use of non-destructive alamarBlue ${ }^{\circledR}$ assay, as previously described (Tierney et al., 2013). Cell-seeded scaffolds were incubated in the alamarBlue solution (Invitrogen, Carlsbad, CA, USA) with gentle shaking for $1 \mathrm{~h}$. The reduction of resazurin to the fluorescent resorufin by metabolically active cells in the solution was measured on a fluorescent spectrophotometer. Relative cell metabolic activity was determined from a standard curve generated from known cell numbers prior to seeding and reported as a percentage of the total number of seeded cells.

\section{RNA isolation and real-time PCR}

RNA was extracted from the MSC-seeded scaffolds at day 1, 4, 7 and 14, using an RNeasy plant mini kit (Qiagen, Valencia, CA, USA). Next, RNA was reverse transcribed to cDNA in a Bio-Rad S1000 thermal cycler, using the QuantiTect reverse transcription kit (Qiagen, Valencia, CA, USA) as previously described (Caliari et al., 2012; Duffy et al., 2011). Real-time PCR reactions were carried out in triplicate, using $10 \mathrm{ng}$ of cDNA and QuantiTect SYBR Green PCR kit (Qiagen, Valencia, CA, USA) in a 7900HT Fast Real-Time PCR system (Carlsbad, CA, USA). The primers used were consistent with previous studies and were synthesised by Integrated DNA Technologies (Coralville, IA, USA). The expression level of the following markers was quantified: collagen type I alpha 2 (COLIA2), collagen type III alpha 1 (COL3A1), cartilage oligomeric matrix protein (COMP), decorin (DCN), scleraxis (SCXB), tenascin-c (TCN), Mohawk homeobox (MKX) and glyceraldehyde 3-phosphate dehydrogenase (GAPDH), which was used as a house keeping gene (Table $1)$. Results were generated using the $\Delta \Delta \mathrm{Ct}$ method and expressed as fold changes, normalised to the expression levels of MSCs at the time of seeding.

\section{Statistical analysis}

One-way analysis of variance (ANOVA) was performed on western blot, metabolic activity, cell number and gene expression data sets (independent variable: strain condition) followed by Tukey-honest significant difference post hoc tests. Significance was set at $p<0.05$. All statistical analyses, performed in R. Scaffolds from three independent experiments, were analysed at each time point for all metrics. Error is reported in figures as the standard error of the mean, unless otherwise noted.
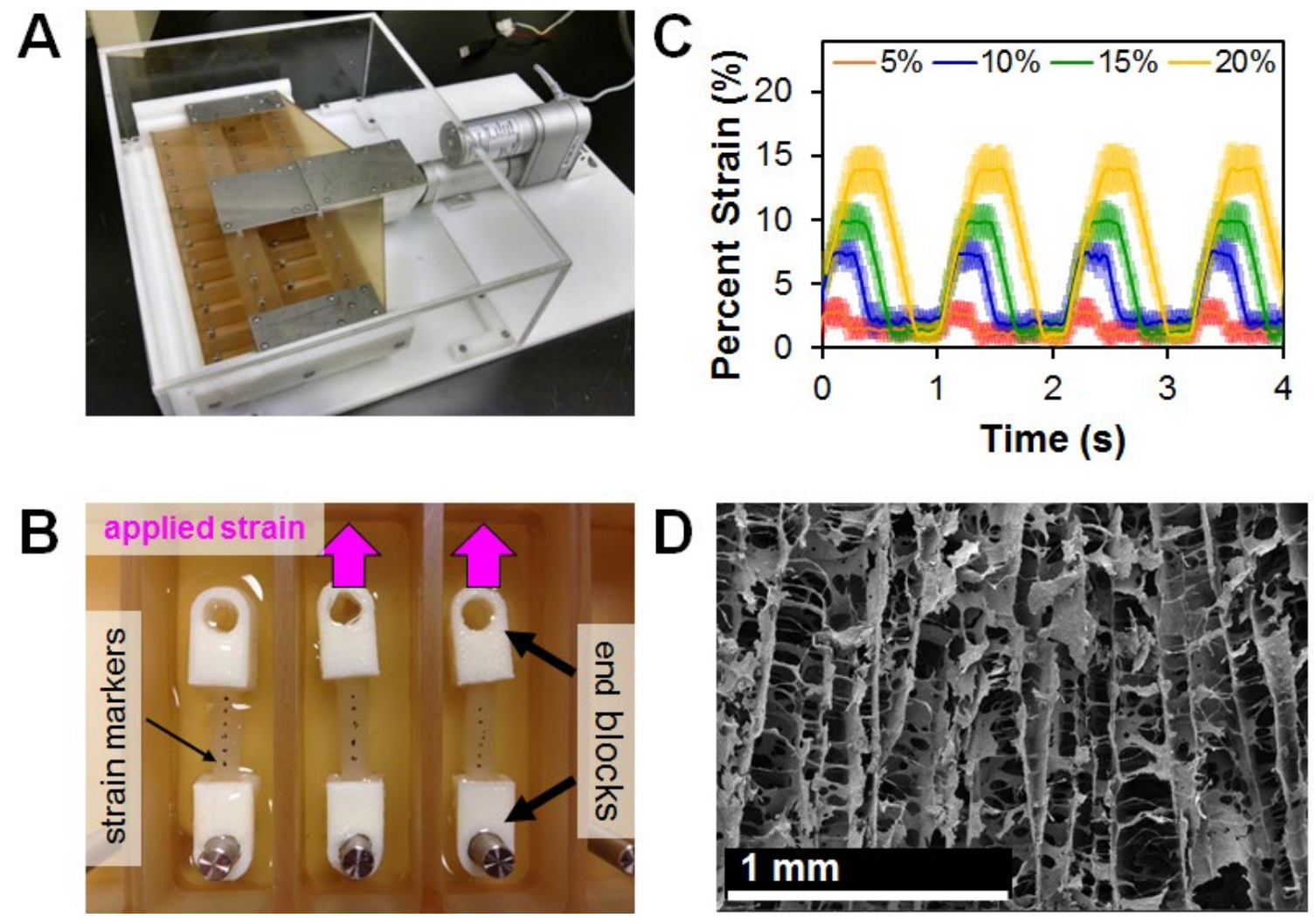

Fig. 1. Custom cyclic strain bioreactor. (A) Custom bioreactor designed with 24 individual wells with static loading posts and moveable rake controlled by a programmable linear actuator. (B) Scaffolds (with fiduciary marks) embedded into hollow PLA end-blocks that can be attached on either end to the static loading post and movable rake within the bioreactor. (C) SEM image of aligned scaffold pore microstructure. Scale bar: $1 \mathrm{~mm}$. (D) Superimposition of measured scaffold deformation in response to a range of system applied cyclic strain amplitudes $(5-20 \%$, all $1 \mathrm{~Hz})$. Scaffold deformation is shown as mean \pm SEM. 


\section{Results}

Identifying the duration of tensile strain required to activate MSC mechanotransduction pathways within CG scaffolds

First, we examined whether the level of applied strain (5, 10 and $15 \%$ strain) altered the activation of MSC mechanotransduction pathway and found no significant difference in activation with different level of tensile strain (data not shown). As a result, and inspired by previous studies showing optimal ligament cell response to $10 \%$ strain (Paxton et al., 2012), all subsequent studies were performed at $10 \% \mathrm{CTS}$. Initial activation of MSC mechanotransduction pathways in response to $10 \% \mathrm{CTS}$ at $1 \mathrm{~Hz}$ were monitored for up to $2 \mathrm{~h}$ of continuous strain application. ROCK1 expression was significantly reduced within $10 \mathrm{~min}$ of application of cyclic strain and remained reduced for up to $2 \mathrm{~h}$ of CTS (Fig. 2A). Maximal activation of ERK 1/2 was seen after 10 min of CTS stimulation, but was significantly reduced when CTS was maintained for longer time periods ( $30 \mathrm{~min}, 2 \mathrm{~h}$ ). The reduction in ERK 1/2 activation was associated with an increase in p38 activity starting from $30 \mathrm{~min}$ of CTS (Fig. 2B). In order to maximise ERK 1/2 activation for long-term, subsequent experiments used an intermittent strain paradigm with 10 min of CTS followed by $5 \mathrm{~h}$ and $50 \mathrm{~min}$ rest, to facilitate recovery of baseline ERK 1/2 and p38 expression (Paxton et al., 2012).
Intermittent tensile strain alters MSC proliferation and metabolic activity

MSC metabolic activity and cell number were monitored over the course of $6 \mathrm{~d}$ of culture with and without CTS (10\% strain, $1 \mathrm{~Hz}$, for 10 min every $6 \mathrm{~h}$ ). While not statistically significant ( $p=0.12$ ), MSCs subjected to CTS trended towards increased metabolic activity during the first $3 \mathrm{~d}$ of culture. However, by the end of the day 6 , there was no noticeable increase or decrease in the metabolic activity of the cell populations with or without CTS (Fig. $3 \mathbf{A})$. While there were no significant changes in total cell number in the scaffolds between day 1 and 6 within either the static or CTS cultures, static cultures showed significantly greater total number of cells compared to CTS at day 6 (Fig. 3B) $(p<0.01)$, suggesting the metabolic activity per cell is enhanced in response to CTS throughout the experiment.

\section{Cyclic tensile strain promotes activation of tendon- related genes}

Subsequently, we examined the expression levels of the tendon-phenotype related genes TNC, MKX and SCXB. The tenogenic transcription factor SCXB was significantly upregulated from $24 \mathrm{~h}(p=0.017)$ in response to CTS and was found to be strongly expressed in CTS culture up to day 6 (Fig. 4A). Expression levels of the transcription factor MKX and tendon-associated glycoprotein TNC showed
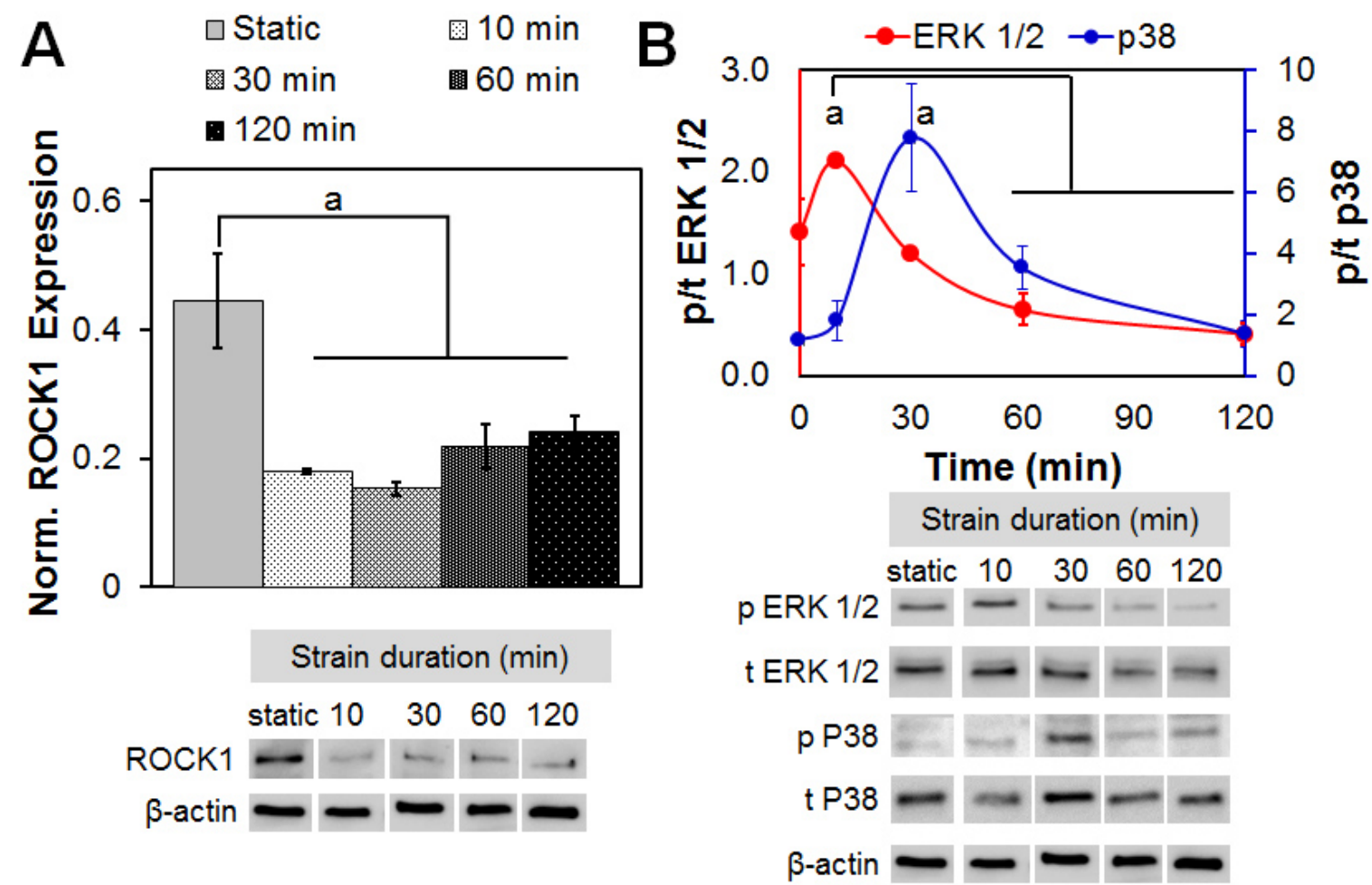

Fig. 2. Rapid activation of mechanotransduction pathways with applied cyclic tensile strain. (A) Expression of ROCK1 normalised to $\beta$-actin expression, as a function of strain cycle duration is rapidly downregulated in response to CTS (all at $10 \%$ strain, $1 \mathrm{~Hz}$ ). (B) MSCs in CG scaffolds showed a sequential increase in the ratio of active (phosphorylated) to total protein for ERK 1/2 (p/t ERK 1/2) and p38 MAPK (p/t p38), normalised to the ratio seen under static conditions, as a function of increasing time of applied CTS (10\% applied system strain, $1 \mathrm{~Hz})$. Data

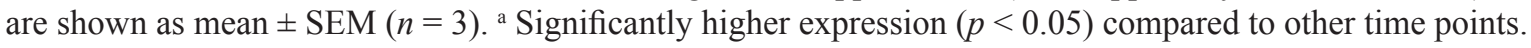


A

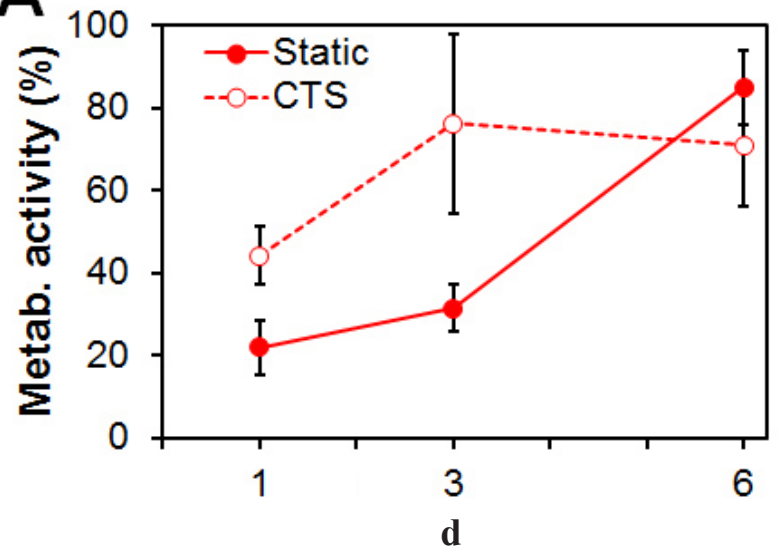

B

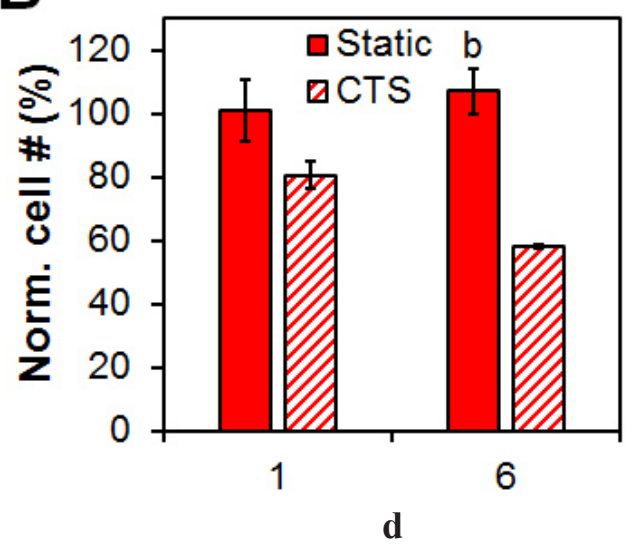

Fig. 3. MSC viability in CG scaffolds undergoing CTS. (A) Metabolic activity of MSCs in CG scaffolds in either static culture or exposed to repeated cycles of CTS (10 min at $10 \%$ strain and $1 \mathrm{~Hz}$ ) followed by $5 \mathrm{~h}$ and $50 \mathrm{~min}$ recovery at day 1, 3 and 6. (B) Normalised number of cells (relative to number initially seeded) at day 1 and 6 in both static and CTS groups. Data are represented as mean $\pm \operatorname{SEM}(n=3)$. ${ }^{\mathrm{b}}$ Significantly higher $(p<0.05)$ compared to CTS group at same day.

little difference between CTS and static groups at day 1 and 3 (Fig. 4B,C). While not always significant, expression levels for all three genes trended towards being increased after $6 \mathrm{~d}$ with CTS, when compared to day 1 .

\section{Cyclic tensile strain promotes activation of ECM biosynthesis related genes}

Next, we examined the effect of CTS on the expression of tendon-associated matrix biosynthesis genes. Expression levels of the primary tendon matrix component COL1A2 was similarly expressed between CTS and static culture, throughout the duration of the $6 \mathrm{~d}$ culture (Fig. 5A). However, levels of COL3A1, a critical element of tendon healing, due to its ability to catalyse formation of rapid crosslinks for stabilising the repair site (Liu et al., 1995), increased significantly after day 3 and 6 with CTS. By day 6 , COL3A1 expression was significantly higher in response to CTS versus static culture $(p=0.024)$ (Fig. 5B). DCN, a regulator of the assembly of collagen fibrils during tendon development (Zhang et al., 2006), was found to increase at each time point in the anisotropic scaffolds and its expression was significantly higher after $6 \mathrm{~d}$ with CTS (Fig. 5C). Also, CTS promoted higher expression levels of the tendon-associated matrix gene COMP at all three time points, especially at day 6 (Fig. 5D), where expression levels in the static control group were almost completely lost $(p<0.001)$.

\section{Smad 2/3 pathway is activated in the presence of cyclic tensile strain}

The activation of the Smad 2/3 and Smad 1/5/8 pathways in MSCs within the CG scaffold was evaluated after $24 \mathrm{~h}$ of CTS and again after $6 \mathrm{~d}$ of culture. At day 6 , expression levels of Smad 2/3 were significantly increased in MSCs within scaffolds cultured under CTS conditions (Fig. 6A). However, activation of the Smad 1/5/8 pathway was not significantly altered by the application of cyclic strain at the time points examined (Fig. 6B).

\section{Discussion}

Mechanical stimulation, in the form of cyclic tensile strain, has been shown to be a critical regulator in the development of the tendon enthesis and in the regulation of stem cell fate decisions (Blitz et al., 2009; Murchison et al., 2007; Pryce et al., 2009; Schweitzer et al., 2010). Our group has recently described an approach to fabricate CG scaffolds with an anisotropic pore geometry that is suitable for tendon tissue engineering applications (Caliari and Harley, 2011). While the porous anisotropic CG scaffolds have been previously shown to support both the stable culture of differentiated tenocytes (Caliari et al., 2012; Grier et al., 2017) as well as the induction of tenogenic differentiation in MSCs (Caliari and Harley, 2014b), this work focused on the development of a custom bioreactor system to facilitate studies on mechanical stimulation of human MSCs in porous anisotropic CG scaffolds. Previous work, using a variety of $2 \mathrm{D}$ and $3 \mathrm{D}$ constructs, has shown that a number of protein kinases are activated in mesenchymal stem cells in response to tensile strain (Arnoczky et al., 2002; Banes et al., 1995; Wang et al., 2001). In particular, ERK 1/2 is believed to play an important role in the stretch-activated increase of collagen production (Papakrivopoulou et al., 2004), making it an important target for development of tendon repair biomaterial. To examine the effect of CTS on MSC response within the CG scaffold, we developed a 24-well tensile strain bioreactor inspired by previous work of Vanderploeg et al. (2008) that allows the isolation of individual samples and/or media at intermediate time-points, to evaluate a range of different metrics. The programmable nature of the linear actuator further allows for easily tuneable culture conditions (strain amplitude, rate, durations; refractory period) and the modular design enables adaptation to fit a wide range of scaffold geometries. In order to facilitate attachment of scaffolds within the bioreactor, a method inspired by the Temenoff laboratory's procedure, using end-blocks to fix hydrogels 
A

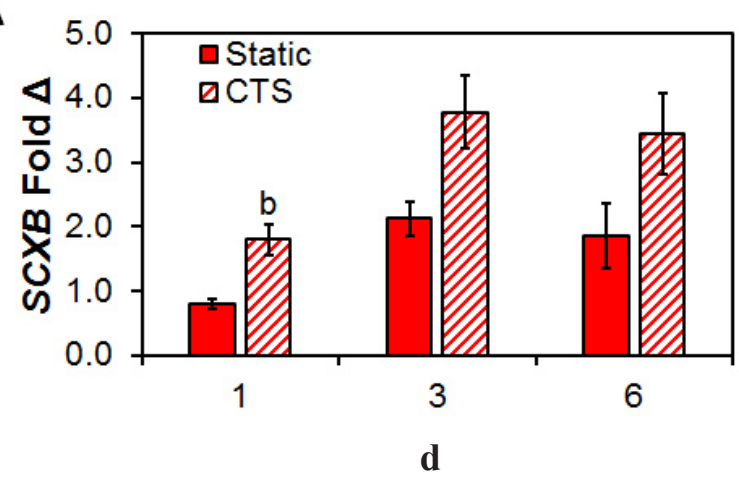

B

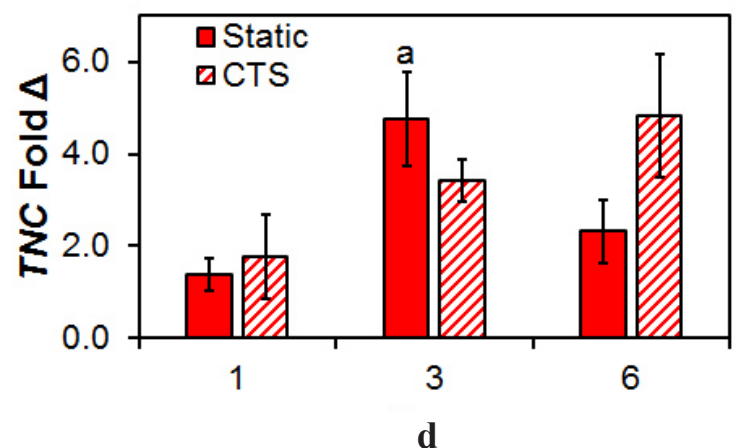

C

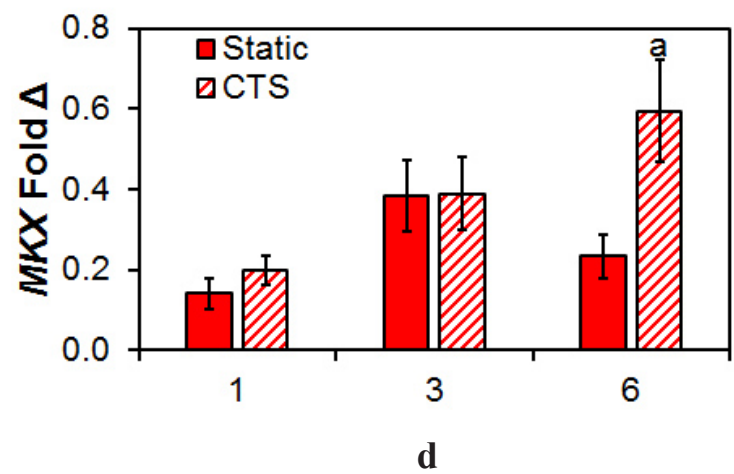

Fig. 4. Changes on pro-tenogenic gene expression profiles in response to CTS. Expression levels of (A) SCXB, (B) TNC and (C) MKX at day 1, 3 and 6 relative to cells at the time of seeding in both static and CTS groups. Data are shown as mean $\pm \operatorname{SEM}(n=3)$. ${ }^{\mathrm{b}}$ Significantly higher expression $(p<0.05)$ than static group at same day. ${ }^{a}$ Significantly higher expression $(p<0.05)$ than day 1 within the same group.

between two posts, was employed (Doroski et al., 2010). By embedding the scaffold ends into hollow end-blocks with PDMS, we were able to avoid scaffold deformation, tearing or slippage as commonly seen with the traditional use of clamps.

This work concentrated on initial metrics of MSC response to applied cyclic strain for up to $6 \mathrm{~d}$. While not long enough to demonstrate extensive matrix remodelling in response to CTS, it allowed us to define MSC protein kinase response to applied cyclic tensile strain using CG scaffolds, with results consistent with the antagonistic roles of ERK $1 / 2$ and $\mathrm{p} 38$ seen in 2D and 3D biomaterials (Arnoczky et al., 2002; Banes et al., 1995; Wang et al.,
2001). Indeed, our examination of MSC response within porous collagen scaffolds within a tensile bioreactor showed time-resolved activation of ERK $1 / 2$ and p38 on a time scale of 10 to $30 \mathrm{~min}$, consistent with previous result for Achilles tendon fibroblasts in fibrin hydrogels, as reported by Paxton et al. (2012). More significantly, we showed that the combination of CTS and an anisotropic CG scaffold is sufficient to establish critical cellular signatures of early tendon development in MSCs. CTS did not lead to negative effects on cell proliferation and in fact it increased metabolic activity per cell. Further, gene expression levels of markers of early tenogenic development (SCXB, TNC, MKX) as well as tendon-associated extracellular matrix proteins (COL3A1, COMP, DCN) were all generally elevated after $6 \mathrm{~d}$ in culture with mechanical stimulation. Indeed, the significant drop in COMP expression in static culture suggests that not only CTS can provide significant positive influence on remodelling associated genes, but that a lack of tensile stimulation has significant negative effects on cell activity and remodelling potential over time. This upregulation of traditional tendon markers, when taken in combination with the increase in metabolic activity on a per cell basis, demonstrates that CTS promotes robust differentiation of metabolically active MSCs towards an early tendon phenotype on aligned CG scaffolds.

While previous work in our laboratory showed that an anisotropic microstructure was sufficient to drive initial tenogenic differentiation of MSCs within $7 \mathrm{~d}$ (Caliari and Harley, 2014b), the biomaterial alone did not provide an adequate environment to promote robust expression of remodelling associated genes. With the development of this bioreactor system, we showed that intermittent cyclic tensile strain, when applied in an appropriate manner, can be used to improve MSC metabolic activity, enhance tenogenic differentiation and show enhanced expression levels of key tendon-associated ECM compounds (DCN, COMP, COL3A1). However, the lack of increase in other matrix remodelling genes such as COL1A2 after $7 \mathrm{~d}$ suggest the need for longer bioreactor cultures in future experiments. Our results also suggested the opportunity to continue exploring the canonical versus non-canonical activation of Smad 2/3. While previous efforts have largely concentrated on $2 \mathrm{D}$ cell cultures, our efforts using anisotropic $\mathrm{CG}$ scaffolds demonstrated preferential activation of Smad 2/3 and enhanced tenogenic differentiation within $6 \mathrm{~d}$ of CTS, a finding well-aligned with previously reported responses. Cytoskeletal tension and matrix mechanical signals are known critical factors for Smad activation and TGF- $\beta$ production (Allen et al., 2012; Rys et al., 2016; Skutek et al., 2001). Further, heightened ERK $1 / 2$ activity is a known element of non-canonical Smad pathway activation (Hayashida et al., 2003). Together, this suggests that CTS applied to MSC-seeded CG scaffolds might drive noncanonical Smad activity via enhanced ERK 1/2 activation, leading to tenogenic differentiation as well as endogenous production of TGF- $\beta$ family growth factors, which might then lead to canonical Smad 2/3 activation and enhanced tenogenic differentiation. While the presence of such an autocatalytic feedback loop is not the subject of this project, ongoing analyses, employing the bioreactor system here developed and validated, aim to better elucidate the 
A

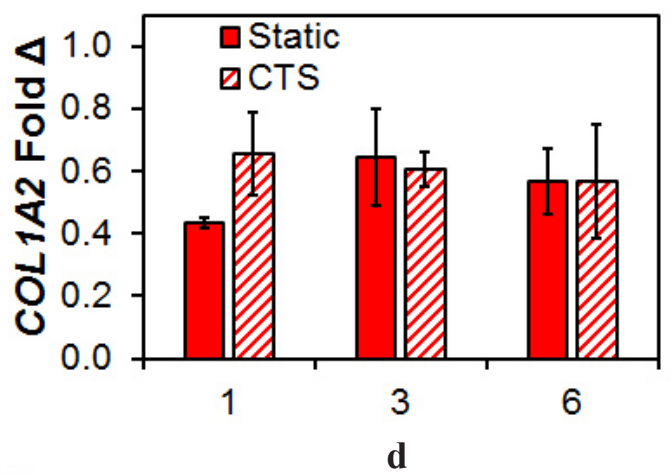

C

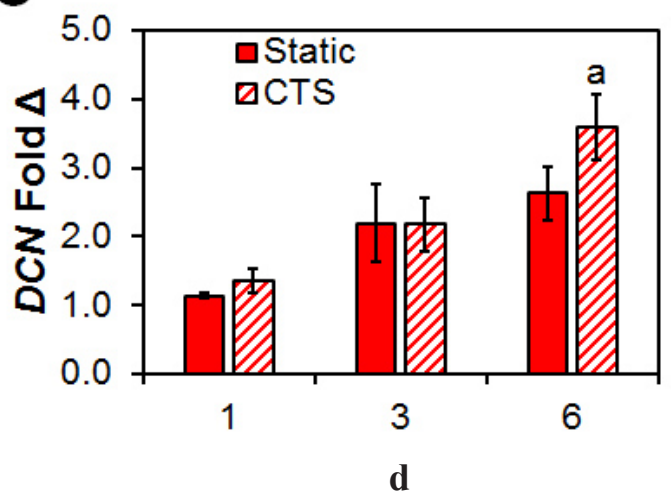

B

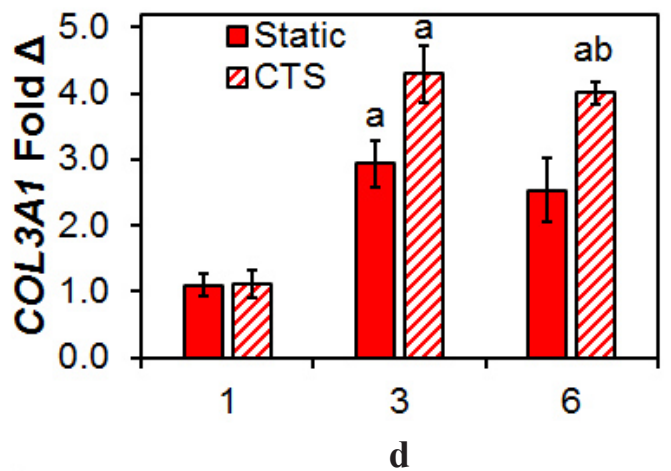

D

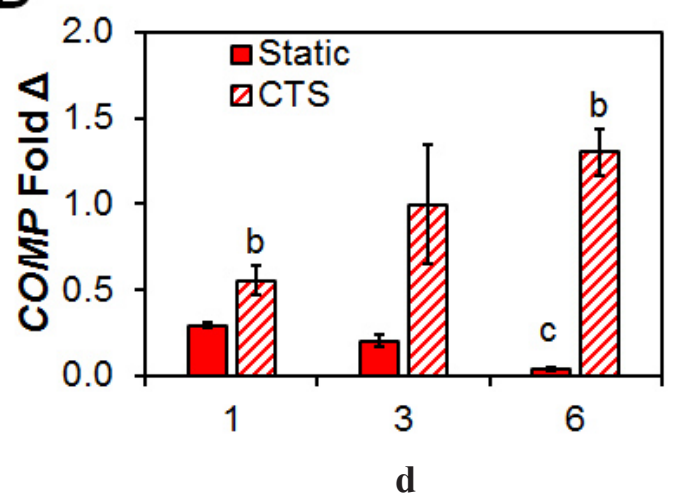

Fig. 5. Changes in structural protein gene expression in response to CTS. Expression levels of (A) COL1A2, (B) COL3A1, (C) DCN and (D) COMP at day 1, 3 and 6, relative to cells at the time of seeding in both static and CTS groups. Data are shown as mean $\pm \operatorname{SEM}(n=3) .{ }^{\mathrm{b}}$ Significantly higher expression $(p<0.05)$ than static group at same day. ${ }^{\text {a }}$ Significantly higher expression $(p<0.05)$ than day 1 within the same group. ${ }^{\mathrm{c}}$ Significantly lower expression $(p<0.05)$ than both day 1 and day 3 within the same group.
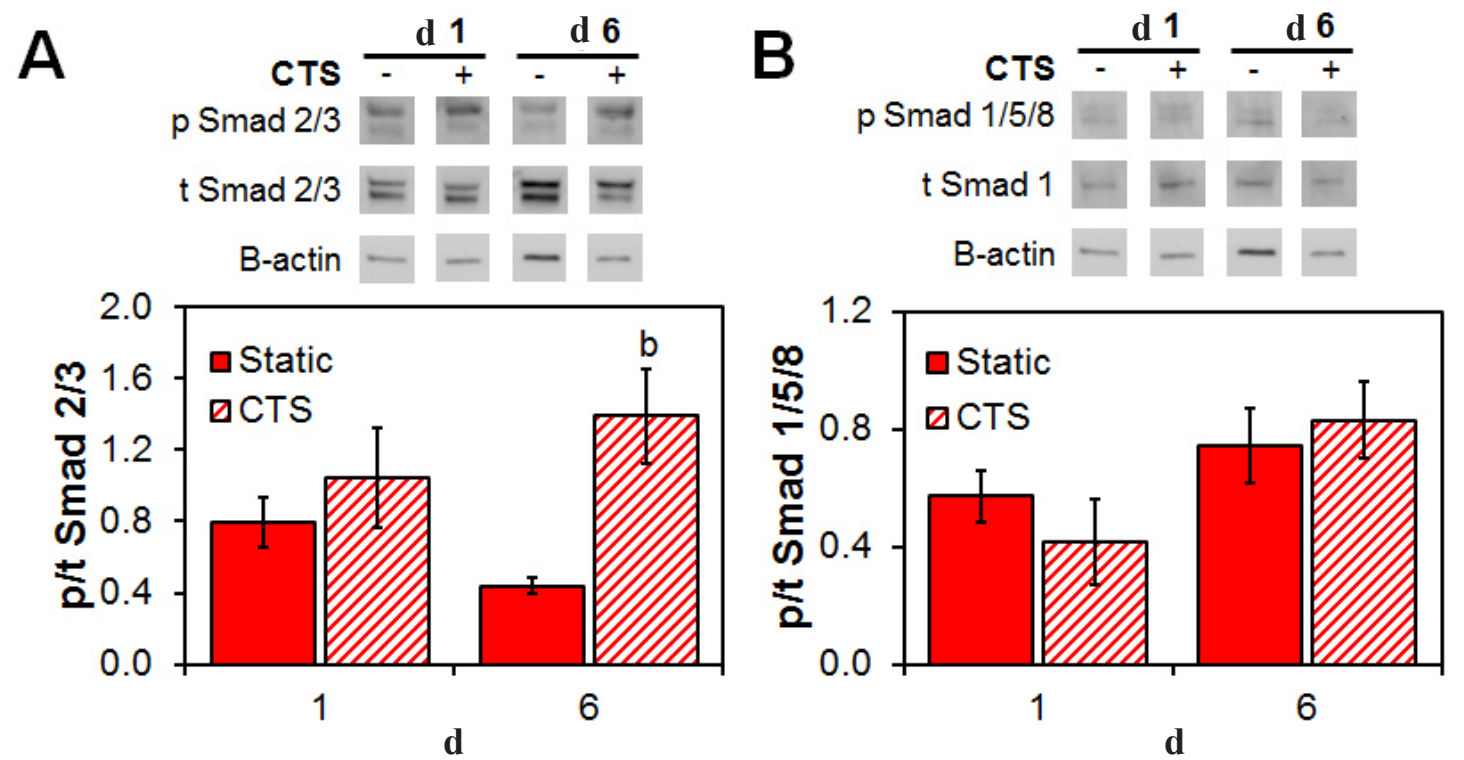

Fig. 6. Differences in the activation of canonical $v s$. non-canonical Smad pathways for MSCs within the CG scaffold in response to CTS. Relative phosphorylation of (A) the non-canonical Smad 2/3 and (B) the canonical Smad $1 / 5 / 8$ at day 1 and 6 as determined by immunoblot. Data are represented as mean \pm SEM $(n=3) .{ }^{\mathrm{b}}$ Significantly higher expression $(p<0.05)$ than static group at same day. 
relationship between CTS, TGF- $\beta$ associated growth factor signalling, Smad activation and the role that these pathways play in the regulation of musculoskeletal tissue development. Such efforts will also allow for a more focused approach to develop long-term culture systems to study in vitro scaffold remodelling and more mature tendon development.

\section{Conclusions}

This work demonstrated the use of a custom-designed cyclic tensile strain bioreactor to mechanically stimulate human MSCs in anisotropic CG scaffolds as a means to enhance proliferation and tenogenic differentiation. Intermittent CTS (10\% applied strain, $1 \mathrm{~Hz}, 10 \mathrm{~min}$ every $6 \mathrm{~h}$ ) was found to rapidly, stably upregulate mechanosensitive protein kinase activity. MSCs showed increased gene expression profiles of a range of tendonrelated ECM proteins and phenotypic markers in response to CTS over the course of the experiment in the presence of applied CTS. Interestingly, we also found that $\mathrm{Smad} 2 / 3$, but not Smad 1/5/8, was preferentially activated in MSCs exposed to extended CTS. This work demonstrates a pathway to refine mechanical stimulation protocols to enhance tenogenic differentiation and matrix biosynthesis for tendon repair applications. Given the design of the bioreactor that affords separate culture of each specimen, these findings also highlight significant opportunities to further define the role played by CTS on the endogenous production of growth factors that may further refine MSC differentiation and matrix biosynthesis.

\section{Acknowledgements}

W.K.G. and B.A.H designed the research; W.K.G. and A.S.M. performed the research; W.K.G., A.S.M. and B.A.H. analysed the data; W.K.G. and B.A.H. wrote the paper.

The authors would like to acknowledge the Carl R. Woese Institute for Genomic Biology Core Facilities for assistance with real-time PCR system. Research reported in this publication was supported by the National Institute of Arthritis and Musculoskeletal and Skin Diseases of the National Institutes of Health under Award Numbers R03 AR062811 and R21 AR063331. We are grateful for funding provided by the Chemistry-Biology Interface Training Program NIH NIGMS T32GM070421 (WKG). Additional support was provided by the Chemical and Biomolecular Engineering Deptartment and the Carl R. Woese Institute for Genomic Biology $(\mathrm{BACH})$ at the University of Illinois at Urbana-Champaign. This research was carried out in part in the Frederick Seitz Materials Research Laboratory Central Facilities, University of Illinois, which are partially supported by the U.S. Department of Energy under grants DE-FG02-07ER46453 and DE-FG02-07ER46471.

\section{References}

Allen JL, Cooke ME, Alliston T (2012) ECM stiffness primes the TGF $\beta$ pathway to promote chondrocyte differentiation. Mol Biol Cell 23: 3731-3742.

Andalib MN, Lee JS, Ha L, Dzenis Y, Lim JY (2013) The role of RhoA kinase (ROCK) in cell alignment on nanofibers. Acta Biomater 8: 7737-7745.

Arnoczky SP, Tian T, Lavagnino M, Gardner K, Schuler P, Morse P (2002) Activation of stress-activated protein kinases (SAPK) in tendon cells following cyclic strain: the effects of strain frequency, strain magnitude, and cytosolic calcium. J Orthop Res 20: 947-952.

Banes AJ, Tsuzaki M, Yamamoto J, Fischer T, Brigman B, Brown T, Miller L (1995) Mechanoreception at the cellular level: the detection, interpretation, and diversity of responses to mechanical signals. Biochem Cell Biol 73: 349-365.

Berthet E, Chen C, Butcher K, Schneider RA, Alliston T, Amirtharajah M (2013) Smad3 binds Scleraxis and Mohawk and regulates tendon matrix organisation. J Orthop Res 31: 1475-1483.

Blitz E, Viukov S, Sharir A, Shwartz Y, Galloway JL, Pryce BA, Johnson RL, Tabin CJ, Schweitzer R, Zelzer E (2009) Bone ridge patterning during musculoskeletal assembly is mediated through SCX regulation of Bmp4 at the tendon-skeleton junction. Dev Cell 17: 861-873.

Bosworth LA, Rathbone SR, Bradley RS, Cartmell SH (2014) Dynamic loading of electrospun yarns guides mesenchymal stem cells towards a tendon lineage. J Mech Behav Biomed Mater 39: 175-183.

Breidenbach AP, Gilday SD, Lalley AL, Dyment NA, Gooch C, Shearn JT, Butler DL (2013) Functional tissue engineering of tendon: establishing biological success criteria for improving tendon repair. J Biomech 9: 19411948.

Caliari SR, Harley BA (2014a) Collagen-GAG scaffold biophysical properties bias MSC lineage choice in the presence of mixed soluble signals. Tissue Eng Part A 20: 2463-2472.

Caliari SR, Harley BAC (2011) The effect of anisotropic collagen-GAG scaffolds and growth factor supplementation on tendon cell recruitment, alignment, and metabolic activity. Biomaterials 32: 5330-5340.

Caliari SR, Harley BAC (2014b) Structural and biochemical modification of a collagen scaffold to selectively enhance MSC tenogenic, chondrogenic, and osteogenic differentiation. Adv Healthc Mater 3: 10861096.

Caliari SR, Weisgerber DW, Ramirez MA, Kelkhoff DO, Harley BA (2012) The influence of collagenglycosaminoglycan scaffold relative density and microstructural anisotropy on tenocyte bioactivity and transcriptomic stability. J Mech Behav Biomed Mater 11: 27-40.

Chen X, Yin Z, Chen J-1, Shen W-1, Liu H-h, Tang Q-m, Fang Z, Lu L-r, Ji J, Ouyang H-w (2012) Force and scleraxis synergistically promote the commitment of human ES cells derived MSCs to tenocytes. Sci Rep 2: 977. 
Doroski DM, Levenston ME, Temenoff JS (2010) Cyclic tensile culture promotes fibroblastic differentiation of marrow stromal cells encapsulated in poly(ethylene glycol)-based hydrogels. Tissue Eng Part A 16: 3457-3466.

Duffy GP, McFadden TM, Byrne EM, Gill SL, Farrell E, O'Brien FJ (2011) Towards in vitro vascularisation of collagen-GAG scaffolds. Eur Cell Mater 21: 15-30.

Engler A, Bacakova L, Newman C, Hategan A, Griffin M, Discher D (2004) Substrate compliance versus ligand density in cell on gel responses. Biophys J 86: 617-628.

Farrell E, O'Brien FJ, Doyle P, Fischer J, Yannas I, Harley BA, O’Connell B, Prendergast PJ, Campbell VA (2006) A collagen-glycosaminoglycan scaffold supports adult rat mesenchymal stem cell differentiation along osteogenic and chondrogenic routes. Tissue Eng12: 459468.

Galatz LM, Sandell LJ, Rothermich SY, Das R, Mastny A, Havlioglu N, Silva MJ, Thomopoulos S (2006) Characteristics of the rat supraspinatus tendon during tendon-to-bone healing after acute injury. J Orthop Res 24: 541-550.

Galloway MT, Lalley AL, Shearn JT (2013) The role of mechanical loading in tendon development, maintenance, injury, and repair. J Bone Joint Surg Am 95: 1620-1628.

Grier WK, Iyoha EM, Harley BAC (2017) The influence of pore size and stiffness on tenocyte bioactivity and transcriptomic stability in collagen-GAG scaffolds. J Mech Behav Biomed Mater 65: 295-305.

Hao J, Zhang Y, Ye R, Zheng Y, Zhao Z, Li J (2013) Mechanotransduction in cancer stem cells. Cell Biol Int 37: 888-891.

Harley BA, Freyman TM, Wong MQ, Gibson LJ (2007a) A new technique for calculating individual dermal fibroblast contractile forces generated within collagenGAG scaffolds. Biophys J 93: 2911-2922.

Harley BA, Kim HD, Zaman MH, Yannas IV, Lauffenburger DA, Gibson LJ (2008) Microarchitecture of three-dimensional scaffolds influences cell migration behavior via junction interactions. Biophys J 95: 4013 4024.

Harley BA, Leung JH, Silva ECCM, Gibson LJ (2007b) Mechanical characterisation of collagenglycosaminoglycan scaffolds. Acta Biomater 3: 463-474.

Harley BA, Spilker MH, Wu JW, Asano K, Hsu HP, Spector M, Yannas IV (2004) Optimal degradation rate for collagen chambers used for regeneration of peripheral nerves over long gaps. Cells Tissues Organs 176: 1-3.

Hayashida T, Decaestecker M, Schnaper HW (2003) Cross-talk between ERK MAP kinase and Smad signaling pathways enhances TGF-beta-dependent responses in human mesangial cells. FASEB J 17: 1576-1578.

James R, Kesturu G, Balian G, Chhabra AB (2008) Tendon: biology, biomechanics, repair, growth factors, and evolving treatment options. J Hand Surg Am 33: 102-112.

Janmey PA, McCulloch CA (2007) Cell mechanics: integrating cell responses to mechanical stimuli. Annu Rev Biomed Eng 9: 1-34.

Kanazawa T, Furumatsu T, Matsumoto-Ogawa E, Maehara A, Ozaki T (2014) Role of Rho small GTPases in meniscus cells. J Orthop Res 32: 1479-1486.
Kim Y-J, Sah RLY, Doong J-YH, Grodzinsky AJ (1988) Fluorometric assay of DNA in cartilage explants using Hoechst 33258. Anal Biochem 174: 168-176.

Laboureau J, Dubertret L, Lebreton-De Coster C, Coulomb B (2004) ERK activation by mechanical strain is regulated by the small $\mathrm{G}$ proteins rac-1 and rhoA. ExpDermatol 13: 70-77.

Liu SH, Yang RS, al-Shaikh R, Lane JM (1995) Collagen in tendon, ligament, and bone healing. A current review. Clin Orthop Relat Res: 265-278.

Liu Y, Ramanath HS, Wang DA (2008) Tendon tissue engineering using scaffold enhancing strategies. Trends Biotechnol 26: 201-209.

Madaghiele M, Sannino A, Yannas IV, Spector M (2008) Collagen-based matrices with axially oriented pores. J Biomed Mater Res A 85: 757-767.

Maeda T, Sakabe T, Sunaga A, Sakai K, Rivera AL, Keene DR, Sasaki T, Stavnezer E, Iannotti J, Schweitzer R, Ilic D, Baskaran H, Sakai T (2011) Conversion of mechanical force into TGF-beta-mediated biochemical signals. Curr Biol 21: 933-941.

Miyazono K (2000) TGF-beta signaling by Smad proteins. Cytokine Growth Factor Rev 11: 15-22.

Mozdzen LC, Rodgers R, Banks JM, Bailey RC, Harley BAC (2016) Increasing the strength and bioactivity of collagen scaffolds using customisable arrays of 3D-printed polymer fibers. Acta Biomater 15: 25-33.

Mozdzen LC, Vucetic A, Harley BAC (2017) Modifying the strength and strain concentration profile within collagen scaffolds using customisable arrays of poly-lactic acid fibers. J Mech Behav Biomed Mater 66: 28-36.

Murchison ND, Price BA, Conner DA, Keene DR, Olson EN, Tabin CJ, Schweitzer R (2007) Regulation of tendon differentiation by scleraxis distinguishes forcetransmitting tendons from muscle-anchoring tendons. Development 134: 2697-2708.

O’Brien FJ, Harley BA, Yannas IV, Gibson LJ (2005) The effect of pore size on cell adhesion in collagen-GAG scaffolds. Biomaterials 26: 433-441.

O’Brien FJ, Harley BA, Yannas IV, Gibson L (2004) Influence of freezing rate on pore structure in freeze-dried collagen-GAG scaffolds. Biomaterials 25: 1077-1086.

Olde Damink LHH, Dijkstra PJ, van Luyn MJA, van Wachem PB, Nieuwenhuis P, Feijen J (1996) Crosslinking of dermal sheep collagen using a water-soluble carbodiimide. Biomaterials 17: 765-773.

Papakrivopoulou J, Lindahl GE, Bishop JE, Laurent GJ (2004) Differential roles of extracellular signal-regulated kinase $1 / 2$ and p38MAPK in mechanical load-induced procollagen $\alpha 1$ (I) gene expression in cardiac fibroblasts. Cardiovasc Res 4: 736-744.

Paxton JZ, Hagerty P, Andrick JJ, Baar K (2012) Optimising an intermittent stretch paradigm using ERK1/2 phosphorylation results in increased collagen synthesis in engineered ligaments. Tissue Eng Part A 18: 277-284.

Pedowitz D, Kirwan G (2013) Achilles tendon ruptures. Curr Rev Musculoskelet Med 6: 285-293.

Pryce BA, Watson SS, Murchison ND, Staverosky JA, Dunker N, Schweitzer R (2009) Recruitment and 
maintenance of tendon progenitors by TGFbeta signaling are essential for tendon formation. Development 136: 1351-1361.

Rys JP, Monteiro DA, Alliston T (2016) Mechanobiology of TGFbeta signaling in the skeleton. Matrix Biol 52-54: 413-425.

Sarasa-Renedo A, Tunç-Civelek V, Chiquet M (2006) Role of RhoA/ROCK-dependent actin contractility in the induction of tenascin-C by cyclic tensile strain. Exp Cell Res 312: 1361-1370.

Schulz Torres D, M. Freyman T, Yannas IV, Spector M (2000) Tendon cell contraction of collagen-GAG matrices in vitro: effect of cross-linking. Biomaterials 21: 1607 1619.

Schweitzer R, Zelzer E, Volk T (2010) Connecting muscles to tendons: tendons and musculoskeletal development in flies and vertebrates. Development 137: 2807-2817.

Shen H, Gelberman RH, Silva MJ, Sakiyama-Elbert SE, Thomopoulos S (2013) BMP12 induces tenogenic differentiation of adipose-derived stromal cells. PLoS ONE 8: e77613.

Shi Y, Massague J (2003) Mechanisms of TGF-beta signaling from cell membrane to the nucleus. Cell 113: 685-700.

Skutek M, van Griensven M, Zeichen J, Brauer N, Bosch U (2001) Cyclic mechanical stretching modulates secretion pattern of growth factors in human tendon fibroblasts. Eur J Appl Physiol 86: 48-52.

Thomopoulos S, Zampiakis E, Das R, Silva MJ, Gelberman RH (2008) The effect of muscle loading on flexor tendon-to-bone healing in a canine model. J Orthop Res 26: 1611-1617.

Tierney EG, Duffy GP, Cryan SA, Curtin CM, O’Brien FJ (2013) Non-viral gene-activated matrices-next generation constructs for bone repair. Organogenesis 9: 22-28.

Towler DA, Gelberman RH (2006) The alchemy of tendon repair: a primer for the (S)mad scientist. J Clin Invest 116: 863-866.

Vanderploeg EJ, Wilson CG, Levenston ME (2008) Articular chondrocytes derived from distinct tissue zones differentially respond to in vitro oscillatory tensile loading. Osteoarthritis Cartilage 16: 1228-1236.

Vitale MA, Vitale MG, Zivin JG, Braman JP, Bigliani LU, Flatow EL (2007) Rotator cuff repair: an analysis of utility scores and cost-effectiveness. J Shoulder Elbow Surg 16: 181-187.

Wang JG, Miyazu M, Matsushita E, Sokabe M, Naruse K (2001) Uniaxial cyclic stretch induces focal adhesion kinase (FAK) tyrosine phosphorylation followed by mitogen-activated protein kinase (MAPK) activation. Biochem Biophys Res Commun 288: 356-361.

Weinbaum J, Schmidt J, Tranquillo R (2013) Combating adaptation to cyclic stretching by prolonging activation of extracellular signal-regulated kinase. Cell Mol Bioeng 6: 279-286.

Xu B, Song G, Ju Y (2011) Effect of focal adhesion kinase on the regulation of realignment and tenogenic differentiation of human mesenchymal stem cells by mechanical stretch. Connect Tissue Res 52: 373-379.
Xu B, Song G, Ju Y, Li X, Song Y, Watanabe S (2012) RhoA/ROCK, cytoskeletal dynamics, and focal adhesion kinase are required for mechanical stretch-induced tenogenic differentiation of human mesenchymal stem cells. J Cell Physiol 227: 2722-2729.

$\mathrm{Xu}$ Y, Murrell GA (2008) The basic science of tendinopathy. Clin Orthop Relat Res 466: 1528-1538.

Yannas IV, Lee E, Orgill DP, Skrabut EM, Murphy GF (1989) Synthesis and characterisation of a model extracellular matrix that induces partial regeneration of adult mammalian skin. Proc Natl Acad Sci USA 86: 933937.

Zhang G, Ezura Y, Chervoneva I, Robinson PS, Beason DP, Carine ET, Soslowsky LJ, Iozzo RV, Birk DE (2006) Decorin regulates assembly of collagen fibrils and acquisition of biomechanical properties during tendon development. J Cell Biochem 98: 1436-1449.

\section{Discussion with Reviewers}

Sarah Snelling: Did the authors assess ERK and p38 MAPK signalling under static conditions and 10-120 min after strain at time points other than first application of strain? i.e. Did the temporal regulation of the pathways change at later time points. How could this impact their results and future use of the bioreactor system? Authors: Both ERK 1/2 and p38 signalling were evaluated under static conditions. This point has been clarified in the caption for Fig. 2. The p38 pathway did not display any activation under static conditions or until after 30 min of CTS. ERK 1/2 was found to show a low level of phosphorylation under static conditions, then a large increase after $10 \mathrm{~min}$ of cyclic tensile strain, followed by a rapid reduction to levels below the ones observed under static conditions at subsequent time points, which was associated with p38 activation. While we did not evaluate signalling at extended time points after the conclusion of the strain cycle, we expect that signalling would return to the same levels as seen under static conditions before the conclusion of the $6 \mathrm{~h}$ rest period, based on previous reports from Paxton et al. (2012b).

Sarah Snelling What proportion of patients with tendon injury or tendinopathy could potentially be treated with the scaffolds developed in this system?

Authors: The scaffolds and methods developed in this system could potentially be used to treat any patient that displays an injury serious enough to require surgical intervention. There are a number of ways that these materials could be applied in a clinical setting, ranging from a patch that would be used to provide an improved framework for healing alongside current surgical techniques to a full-tendon replacement using patientderived cells.

Osnat Hakimi: Do you see an application of this method only as a research tool or a future application for create neo-tendons?

Authors: We believe that this system not only provides an excellent research tool to better understand the 
differentiation of MSCs and tissue development in an in vitro setting, but also holds promise for clinical translation. While much development remains to be done, ongoing experiments are exploring the combination of material properties and mechanical force on long term markers of tenogenic differentiation and matrix remodelling. These conditions will be critical for identifying strategies to exploit patient-derived cells for a wide range of tendon injuries.

Osnat Hakimi: The strain setting suggested in this study is a generic tendon-forming mechanical setting, but could this vary depending on the tendon in question (for example Achilles vs. Extensor digitorum)?

Authors: We absolutely agree that there is a critical need to understand how the divergent structural and mechanical microenvironments found between positional and energystoring tendons, as well as tendons of different scales, affect tendon regenerative medicine solutions. Solutions for positional vs. energy-storing tendons will likely require significantly different functional set-points in regards to mechanical stimulation and biomaterial structural cues.
Our design of this bioreactor, that includes a programmable linear actuator, allows us to explore a wide range of strain amplitudes and frequencies. Additionally, the modular design of the bioreactor allows us to swap wells and rakes to accommodate scaffolds of differing sizes or geometries. Our ability to precisely control biomaterial microstructure, mechanical properties and extrinsic tensile stimulation offers an exciting platform to investigate tendon-specific mechanoregulation of stem cell activity.

\section{Additional reference}

Paxton JZ, Hagerty P, Andrick JJ, Baar K (2012b) Optimizing an intermittent stretch paradigm using ERK1/2 phosphorylation results in increased collagen synthesis in engineered ligaments. Tissue Eng Part A 18: 277-284.

Editor's note: The Scientific Editor responsible for this paper was Juerg Gasser. 